\title{
A Novel Two-Scale Progressive Failure Analysis Method for Laminated Fiber-Reinforced Composites
}

\author{
Dianyun Zhang*, Deepak K. Patel ${ }^{\dagger}$ and Anthony M. Waas ${ }^{\ddagger}$ \\ Aerospace Engineering, University of Michigan, Ann Arbor, MI, 48109
}

\begin{abstract}
A novel, two-scale computational model has been developed to predict the progressive damage and failure responses of fiber-reinforced composite laminates using the material properties at the constituent (fiber and matrix) level. These properties were measured from coupon level tests on a unidirectional lamina of the same material system. In the proposed computational scheme, the macroscale finite element analysis (FEA) was carried out at the lamina level of a 3D laminate model, while micromechanical analysis was implemented concurrently at the subscale to compute the local fields at the fiber and matrix scale. Thus, the influence of matrix microdamage at the microscale manifests as the progressive degradation of the lamina stiffness, resulting in the nonlinear evolution of the stress versus strain response, while the lamina stiffness matrix remains positive-definite. The lamina post-peak strain softening response resulting from catastrophic failure modes including fiber tensile breakage, fiber kinking and matrix cracking, were modeled using the smeared crack approach (SCA). The interlaminar failure due to delamination was accounted for through cohesive elements inserted in-between the layers. The predictive capability of the proposed method is illustrated by comparing the computational results with experiment for three different lay-ups of IM-7/977-3 carbon fiber composite laminates subjected to various loading conditions, including both un-notched and open-hole specimens subjected to remote tensile and compressive loading, respectively.
\end{abstract}

\section{Introduction}

One of the most important problems in the mechanics of composite materials is the prediction of ultimate strength of multi-directional laminates based upon lamina level constitutive properties that can be measured independently through a set of coupon level tests. However, the hierarchical nature of composites makes the characterization and modeling of such materials a great challenge. With little knowledge on the constituent properties, predictions from computational models may encompass a high level of uncertainty since errors are accumulated and evolved from one hierarchical level to another. For large-scale structural analysis, homogenization at the macroscale is essential to achieve computational efficiency, whereas the model also needs to consider the influence of microstructure since damage and failure progresses at the constituent material scale.

Multiscale modeling, in which information is shared across different scales, is an efficient modeling methodology for heterogeneous materials such as composites. For progressive damage and failure analysis of such materials, the key is to develop an efficient computational scheme at the fiber and matrix level to capture the local stress and strain fields. In the literature, a number of micromechanics model have been developed, as reviewed in. ${ }^{1,2}$ Analytical models, including the concentric cylinder model (CCM), the generalized self-consistent method (GSCM), and the Mori-Tanaka (M-T) method, have been extensively used

${ }^{*}$ Postdoctoral Research Fellow, Aerospace Engineering, University of Michigan, Ann Arbor, MI, 48109.

${ }^{\dagger} \mathrm{PhD}$ Candidate, Aerospace Engineering, University of Michigan, Ann Arbor, MI, 48109.

${ }^{\ddagger}$ Felix Pawlowski Professor, Aerospace Engineering, University of Michigan, Ann Arbor, MI, 48109. From January 1, 2015, Boeing Egtvedt Chair and Chairman, Department of Aeronautics and Astronautics, University of Washington, Seattle. Fellow AIAA.

Copyright (c) 2014 by Dianyun Zhang, Deepak K. Patel and Anthony M. Waas. Published with permission by the American Institute of Aeronautics and Astronautics. 
to compute the composite effective properties in the linear regime. In some instances, these methods can be extended for nonlinear analysis through a secant-modulus approach. ${ }^{3,4,5,6}$ However, since stress concentrations in the constituents are neglected in these homogenization techniques, the solutions usually yield an overestimation of the composite nonlinear response, and therefore they find difficulty in extension to damage and failure analysis of composite structures.

In order to resolve the local fields at the microscale, a multitude of semi-analytical methods have been developed and achieve a better prediction of the composite nonlinear response. These techniques include the subregion method proposed by Nemat-Nasser et al., ${ }^{7}$ the transformation field analysis (TFA) proposed by Dvorak, ${ }^{8,9}$ and its extension, the nonuniform transformation field analysis (NTFA) developed by Michel and Suqent. ${ }^{10}$ In addition, the method of cell (MOC) ${ }^{11}$ and its extension, the generalized method of cell $(\mathrm{GMC}),{ }^{12}$ are another powerful semi-analytical techniques to approximate the composite effective behavior. In the GMC, the composite repeating unit cell (RUC) is divided into subcells that represent fiber and matrix. The continuity conditions of the displacement and traction at the interfaces between subcells and between adjacent RUCs are imposed on a average basis, resulting in a set of equations that relate the local microscopic strains to the global macroscopic strains through a concentration tensor. In order to improve the prediction of the local fields, the high-fidelity generalized method of cells (HFGMC) ${ }^{13}$ was developed , in which the subcell displacement fields are expanded using second-order approximations. The HFGMC has demonstrated the capability in damage and failure analysis at the constituent scales such as fiber-matrix debonding and matrix cracking. ${ }^{14,15,16,17}$

The semi-analytical methods offer a distinct advantage over the analytical methods in that the spatial variations in the local fields are better resolved, and the methods achieve computational advantage over fully numerical methods. However, the computational time increases rapidly if more details of the nonlinear effects in the local fields are required to be captured. Recently, Zhang and Waas ${ }^{18}$ proposed a novel, twoscale model to predict the nonlinear response of unidirectional composites. Using a fiber-matrix concentric cylinder as the basic repeat unit to represent the composite microstructure, micromechanics is used to relate the globally applied strains on the composite to the local strain fields of the fiber and matrix through a six by six transformation matrix. As a result, the evolution of matrix microdamage at the microscale manifests as the progressive degradation of the composite stiffness matrix. This method demonstrates a significant computational advantage since the subscale micromechanical analysis is carried out in closed form, and therefore, it is suitable for large-scale analysis of composite structures including damage tolerance and durability.

The purpose of this paper is to establish a computational framework to predict the progressive damage and failure response of laminated composites using constitutive properties measured from coupon level tests of a unidirectional lamina. Three different lay-ups of IM-7/977-3 carbon fiber composite laminates, including both un-notched and open-hole specimens, are studied. The determination of the constituent properties is provided in Section II. Details of the modeling strategy, including the construction of the finite element (FE) model and the development of the lamina nonlinear constitutive models, are presented in Section III. The predictive capability of the proposed method is evaluated by comparing the computational results of various lay-ups and loading conditions with experiment, as discussed in Section IV.

\section{Characterization of Constituent Properties}

In order to obtain the elastic and failure properties of the IM-7/977-3 lamina, a set of coupon tests, including tension, compression, double cantilever beam (DCB) tests, and end notched flexure (ENF) tests, were carried out at the Air Force Research Laboratory (AFRL). Table 1 summaries the measured lamina properties.

The fiber and matrix properties were obtained based upon measured lamina properties in conjunction with a discrete $3 \mathrm{D}$ FE model in which the lamina was represented by a representative volume element (RVE) that contains 15 randomly distributed fibers, subjected to periodic boundary conditions. The matrix is assumed to be isotropic and behave the same in tension and compression before failure, whereas the carbon fiber is assumed to be transversely isotropic with a different $0^{\circ}$ modulus in tension and compression, respectively. The fiber volume fraction of $64 \%$, which falls within measured ranges of fiber volume fraction, resulted in the computed lamina stiffnesses matching the experimental results in all the loading conditions. The obtained constituent properties, which are required in the subsequent analysis, are summarized in Table 2 .

The polymer matrix shows a nonlinear stress versus strain response before failure due to the evolution 
Table 1. Elastic and failure properties of the IM-7/977-3 lamina.

\begin{tabular}{lcl}
\hline Property & Value & Description \\
\hline$E_{1 T}(\mathrm{GPa})$ & 164.3 & Modulus in fiber direction (0 degree) tension \\
$E_{1 C}(\mathrm{GPa})$ & 137.4 & Modulus in fiber direction (0 degree) compression \\
$E_{2 T}(\mathrm{GPa})$ & 8.977 & Modulus in 90 degree tension \\
$\nu_{12}$ & 0.3197 & Poisson's ratio in fiber direction (0 degree) tension \\
\hline$X_{T}(\mathrm{MPa})$ & 2905 & Maximum stress in fiber direction $(0$ degree) tension \\
$X_{C}(\mathrm{MPa})$ & 1274 & Maximum stress in fiber direction $(0$ degree $)$ compression \\
$Y_{T}(\mathrm{MPa})$ & 44.4 & Maximum stress in 90 degree direction tension \\
$Y_{C}(\mathrm{MPa})$ & 247.6 & Maximum stress in 90 degree direction compression \\
\hline$G_{I C}(\mathrm{~N} / \mathrm{mm})$ & 0.256 & Critical energy release rate for Mode I crack initiation \\
$G_{I I C}(\mathrm{~N} / \mathrm{mm})$ & 1.156 & Critical energy release rate for Mode II crack initiation \\
\hline
\end{tabular}

Table 2. The elastic properties of IM-7 carbon fiber and 977-3 epoxy resin used in this paper.

\begin{tabular}{ccccccc}
\hline & $\begin{array}{c}E_{1 T} \\
(\mathrm{GPa})\end{array}$ & $\begin{array}{c}E_{1 C} \\
(\mathrm{GPa})\end{array}$ & $\begin{array}{c}E_{2} \\
(\mathrm{GPa})\end{array}$ & $\begin{array}{c}\nu_{12} \\
-\end{array}$ & $\begin{array}{c}G_{12} \\
(\mathrm{GPa})\end{array}$ & $\begin{array}{c}G_{23} \\
(\mathrm{GPa})\end{array}$ \\
\hline IM-7 carbon & 256 & 214 & 15 & 0.28 & 15 & 6.3 \\
$977-3$ epoxy & 3.4 & 3.4 & & 0.38 & 1.2 & \\
\hline
\end{tabular}

of matrix microdamage. Previous studies have shown that the matrix inside a fiber-reinforced composite exhibits a different stress-strain response than the virgin resin material. ${ }^{19,20}$ The presence of fibers in a composite introduce a non-uniform temperature distribution on the surrounding matrix during curing, resulting in residual stresses that cause the material to behave differently from the one cured without fibers. Rather than modeling the effect of heat generation and residual stresses due to curing, the matrix can be alternatively modeled using an effective stress-strain response that is obtained directly from a cured composite specimen. Such an effective response is referred to as an in-situ stress-strain relation.

In this research, the matrix in-situ properties were determined from the tension test on a $\pm 45^{\circ}$ symmetric laminate in conjunction with a micromechanics model. Details of this method are provided in. ${ }^{21}$ Furthermore, it is assumed that the matrix nonlinear response can be characterized using an exponential relation,

$$
\sigma_{e q}=\sigma_{y}-\frac{K_{1}}{K_{2}}\left(\mathrm{e}^{-K_{2} \epsilon_{e q}}-\mathrm{e}^{-K_{2} \frac{\sigma_{y}}{E}}\right)
$$

where $\sigma_{y}$ is the yield stress of the matrix in a uniaxial tension test, $E$ is the elastic modulus, $K_{1}$ and $K_{2}$ are the two material constants that govern the evolution of matrix microdamage, and, the equivalent stress, $\sigma_{e q}$, and the equivalent strain, $\epsilon_{e q}$, are computed based upon each stress and strain component as,

$$
\begin{aligned}
\sigma_{e q} & =\sqrt{\frac{1}{2}\left[\left(\sigma_{11}-\sigma_{22}\right)^{2}+\left(\sigma_{22}-\sigma_{33}\right)^{2}+\left(\sigma_{33}-\sigma_{11}\right)^{2}\right]+3\left(\sigma_{12}^{2}+\sigma_{13}^{2}+\sigma_{23}^{2}\right)} \\
\epsilon_{e q} & =\frac{1}{1+\nu_{s}} \sqrt{\frac{1}{2}\left[\left(\epsilon_{11}-\epsilon_{22}\right)^{2}+\left(\epsilon_{22}-\epsilon_{33}\right)^{2}+\left(\epsilon_{33}-\epsilon_{11}\right)^{2}\right]+\frac{3}{4}\left(\gamma_{12}^{2}+\gamma_{13}^{2}+\gamma_{23}^{2}\right)}
\end{aligned}
$$

where $\nu_{s}$ is the matrix secant Poisson's ratio defined by,

$$
\nu_{s}=\frac{1}{2}+\frac{E_{s}}{E}\left(\nu-\frac{1}{2}\right)
$$

and $\nu$ is the elastic Poisson's ratio. Parameters of the matrix nonlinear properties defined in Eq. (1) are presented in Table 3. 
Table 3. Matrix nonlinear properties used in this paper.

\begin{tabular}{ccc}
\hline$\sigma_{y}(\mathrm{MPa})$ & $K_{1}(\mathrm{MPa})$ & $K_{2}$ \\
\hline 48.3 & 3500 & 25 \\
\hline
\end{tabular}

\section{Numerical Model}

The focus of this section is to establish a computational framework to predict the laminate responses using the properties obtained from the lamina-level coupon tests discussed in Section II. Three different lay-ups of IM-7/977-3 composite laminates, as summarized in Table 4, were utilized to access the predictive capability of the model through the tensile and compressive responses of both un-notched and open-hole laminates. The construction of the FE model is presented in Section III.A, followed by the development of lamina constitutive models for the pre-peak nonlinear responses and post-peak softening, which are presented in Section III.B and III.C, respectively.

Table 4. Three different lay-ups of IM-7/977-3 laminates studied in this paper.

\begin{tabular}{cc}
\hline & Lay-up \\
\hline Lay-up 1 & {$[0 / 45 / 90 /-45]_{2 s}$} \\
\hline Lay-up 2 & {$[60 / 0 /-60]_{3 s}$} \\
\hline Lay-up 3 & {$[30 / 60 / 90 /-60 /-30]_{2 s}$} \\
\hline
\end{tabular}

\section{III.A. Construction of the FE model}

The proposed computational strategy was to model each laminate using a full 3D FE model consisting of discrete layers of homogenized laminae, as shown in Figure 1. Each lamina was meshed using 3D linear brick elements. A novel micromechanics model, as presented in Section III.B, was implemented at each integration point to capture the progression of matrix microdamage and compute the lamina stiffness. The failure responses, including fiber tensile breakage, fiber compressive failure, and matrix cracking, were modeled using a continuum scheme based upon phenomenological failure criteria, as discussed in Section III.C. In addition, a layer of cohesive elements was implemented in-between the lamina layers to account for possible delamination. The cohesive layers were consider as pure continuum matrix layers with $5 \%$ of the lamina thickness. It is assumed that these cohesive layers exhibit a linear softening response once the critical stress is reached. Mixed-mode delamination was accounted for through the Benzeggagh-Kenane (B-K) fracture criterion $^{22}$ using the fracture properties shown in Table 1.

The FE models along with the dimensions and boundary conditions that are used for un-notched and open-hole specimens are shown in Figure 2. The finite element analysis (FEA) was carried out using the Abaqus/Standard (version 6.12) dynamic implicit solver.

\section{III.B. Lamina Pre-Peak Nonlinear Response}

The experimental results of the $\pm 45^{\circ}$ symmetric laminate tensile tests indicate that each lamina exhibits a nonlinear stress versus strain response due to the evolution of matrix microdamage developing at the microscale. In the proposed computational scheme, each lamina was homogenized as a 3D solid, therefore, micromechanical analysis must be implemented at the subscale to capture such nonlinear behavior. Recently, Zhang and Waas ${ }^{18}$ developed a two-scale, micromechanics-based model for computing the nonlinear response of a unidirectional composite. In their model, a fiber-matrix concentric cylinder is used as the repeat unit cell (RUC), to represent a composite lamina. Micromechanics is used to relate the globally applied composite strains to the fiber and matrix strains at the microscale through a six by six transformation matrix. Details of this model are given in Section III.B.1, and the implementation within the FE framework is provided in Section III.B.2. 


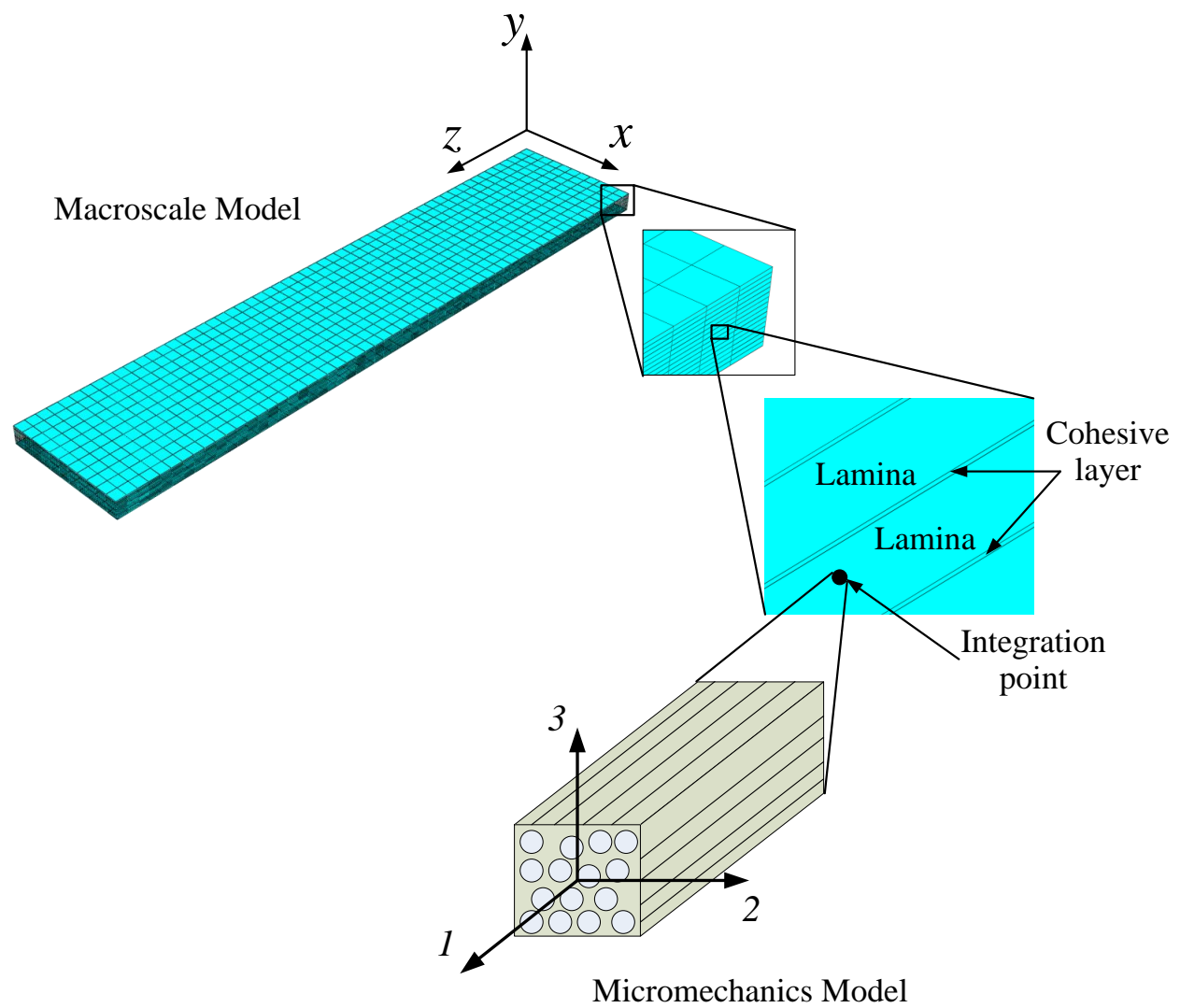

Figure 1. Modeling strategy of the present two-scale model.

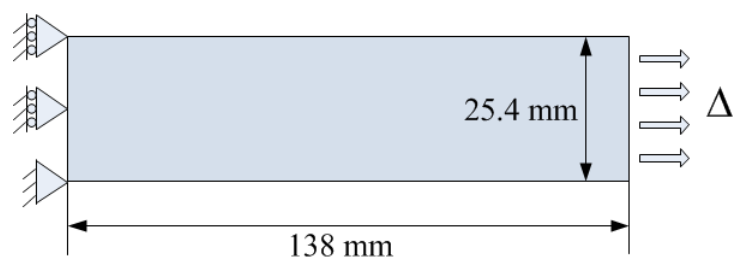

(a) Un-notched tension.

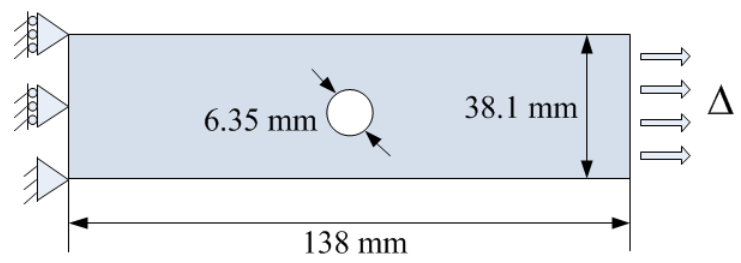

(c) Open hole tension.

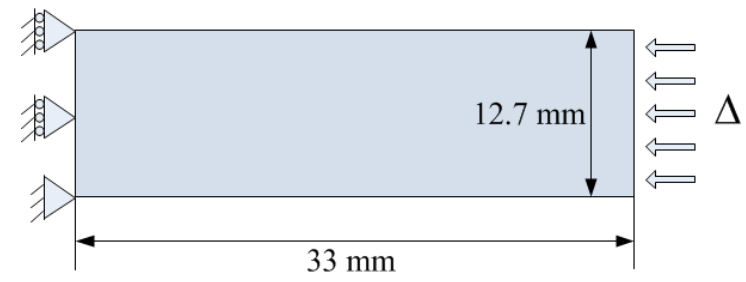

(b) Un-notched compression.

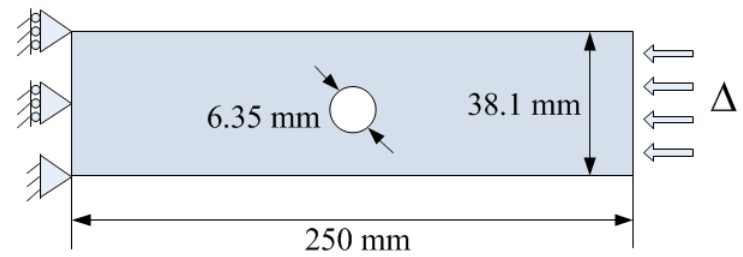

(d) Open hole compression.

Figure 2. Four different loading conditions.

\section{III.B.1. Micromechanics Model}

The microstructure of a unidirectional composite is shown in Figure 1, in which the fibers are assumed to be infinitely long with a statistically isotropic plane that is transverse to the fiber direction. The effective response of such a material is transversely isotropic, requiring five independent constants to form the composite stiffness tensor. Although the choices of these elastic constants are not unique, the axial modulus, $E_{1}^{c}$, the axial Poisson's ratio, $\nu_{12}^{c}$, the axial shear modulus, $G_{12}^{c}$, the plane-strain bulk modulus, $K_{23}^{c}$, and 
the transverse shear modulus, $G_{23}^{c}$, are used throughout the paper. Therefore, the stiffness tensor for a transversely isotropic fiber tow can be written in terms of these elastic constants as,

$$
\boldsymbol{C}^{c}=\left[\begin{array}{cccccc}
E_{1}^{c}+4 \nu_{12}^{c^{2}} K_{23}^{c} & 2 \nu_{12}^{c} K_{23}^{c} & 2 \nu_{12}^{c} K_{23}^{c} & 0 & 0 & 0 \\
2 \nu_{12}^{c} K_{23}^{c} & K_{23}^{c}+G_{23}^{c} & K_{23}^{c}-G_{23}^{c} & 0 & 0 & 0 \\
2 \nu_{12}^{c} K_{23}^{c} & K_{23}^{c}-G_{23}^{c} & K_{23}^{c}+G_{23}^{c} & 0 & 0 & 0 \\
0 & 0 & 0 & G_{23}^{c} & 0 & 0 \\
0 & 0 & 0 & 0 & G_{12}^{c} & 0 \\
0 & 0 & 0 & 0 & 0 & G_{12}^{c}
\end{array}\right]
$$

Other important constants, including the transverse modulus, $E_{2}^{c}$, and transverse Poisson's ratio, $\nu_{23}^{c}$, can be computed as,

$$
\begin{aligned}
E_{2}^{c} & =\frac{4 G_{23}^{c} K_{23}^{c}}{K_{23}^{c}+\psi G_{23}^{c}} \\
\nu_{23}^{c} & =\frac{K_{23}^{c}-\psi G_{23}^{c}}{K_{23}^{c}+\psi G_{23}^{c}}
\end{aligned}
$$

where,

$$
\psi=1+\frac{4 K_{23}^{c} \nu_{12}^{c^{2}}}{E_{1}^{c}}
$$

In the pre-peak nonlinear regime (before catastrophic failure), the fiber is assumed to be linear elastic, transversely isotropic, with "1" designating its longitudinal direction. Its stiffness tensor, $\boldsymbol{C}^{f}$, can be written in terms of fiber properties using Eq. (5) by replacing the superscript "c" with " $\mathrm{f}$ ". The matrix material is an isotropic elastic-damaging solid, and its nonlinear response is modeled using a modified $J_{2}$ deformation theory of plasticity through a secant-modulus approach, as discussed in Section II. As a result, the composite effective stress-strain response is extended to the nonlinear regime by substituting secant moduli into Eq. (5).

The key to the micromechanics model proposed by Zhang and Waas ${ }^{18}$ is to relate the composite strains (the strain applied on the fiber-matrix microstructure) to the local matrix strain fields through a 6 by 6 transformation matrix, $\boldsymbol{F}$, as,

$$
\left\{\begin{array}{l}
\epsilon_{11}^{m} \\
\epsilon_{22}^{m} \\
\epsilon_{33}^{m} \\
\gamma_{12}^{m} \\
\gamma_{13}^{m} \\
\gamma_{23}^{m}
\end{array}\right\}=\left[\begin{array}{llllll}
F_{11} & F_{12} & F_{13} & F_{14} & F_{15} & F_{16} \\
F_{21} & F_{22} & F_{23} & F_{24} & F_{25} & F_{26} \\
F_{31} & F_{32} & F_{33} & F_{34} & F_{35} & F_{36} \\
F_{41} & F_{42} & F_{43} & F_{44} & F_{45} & F_{46} \\
F_{51} & F_{52} & F_{53} & F_{54} & F_{55} & F_{56} \\
F_{61} & F_{62} & F_{63} & F_{64} & F_{65} & F_{66}
\end{array}\right]\left\{\begin{array}{c}
\epsilon_{11}^{c} \\
\epsilon_{22}^{c} \\
\epsilon_{33}^{c} \\
\gamma_{12}^{c} \\
\gamma_{13}^{c} \\
\gamma_{23}^{c}
\end{array}\right\}
$$

The $F_{i j}$ components can be computed by imposing a single non-zero composite strain on the fiber-matrix microstructure and solving the resulting matrix strain fields. In particular, the axial properties, including the axial tension $\left(E_{1}^{c}\right.$ and $\left.\nu_{12}^{c}\right)$ and axial shear $\left(G_{12}^{c}\right)$, are computed through a two-phase concentric cylinder model $(\mathrm{CCM}),{ }^{23}$ which is subsequently used for the computation of $F_{i 1}, F_{i 4}$, and $F_{i 5}$. The rest of the components in the $\boldsymbol{F}$ matrix are determined via an extended three-phase generalized self-consistent model (GSCM) ${ }^{24}$ which also gives the composite transverse properties, $K_{23}^{c}$ and $G_{23}^{c}$. The computation of tow effective properties and each component in the $\boldsymbol{F}$ matrix are provided in appendix A and appendix B, respectively. It should be noted that the proposed micromechanics model is based upon the homogenization technique that was originally used to compute the composite effective moduli, hence, both the fiber and matrix are assumed to be linear elastic. When the matrix stiffness is reduced due to microdamage, the nonlinear response of the matrix is modeled through a secant-modulus approach, in which the matrix elastic properties are replaced with the corresponding secant moduli.

\section{III.B.2. Implementation of the Two-Scale Model}

The modeling methodology for capturing the composite pre-peak nonlinear response was based upon two scales. The lamina-level analysis was conducted by utilizing the homogenized stresses and strains of the 
lamina, while micromechanical analysis was carried out simultaneously at the fiber and matrix level using the closed-form solutions provided in Section III.B.1. The subscale micromechanics model was implemented at each integration point of the lamina-level model, using a user defined material subroutine, UMAT. This subroutine is called at each integration point at each increment, and the material constitutive law is updated through user-defined options.

At the start of each increment, the lamina stress, strain, and solution-dependent state variables from the previous equilibrium step and the strain increments in the current step are passed into the UMAT through the ABAQUS solver. In the $n$th increment, the total strain, $\epsilon_{i j}^{n}$, is calculated by adding the current strain increment, $d \epsilon_{i j}^{n}$, to the strain in the previous step, $\epsilon_{i j}^{n-1}$, as $\epsilon_{i j}^{n}=\epsilon_{i j}^{n-1}+d \epsilon_{i j}^{n}$. In the two-scale modeling scheme, the strains at each integration point in the FE (macroscale) model are applied to the closed-form subscale micromechanics model. These integration point strains can be treated as the effective lamina strains that are applied on the RUC. The constituent strain fields within the RUC therefore can be computed in closed form by knowing the globally applied strains through the $\boldsymbol{F}$ matrix in Eq. (8).

It should be noted that the resulting RUC matrix strain fields vary in space, ${ }^{18}$ hence the matrix equivalent strain, computed using Eq. (3), has a spatial variation as well. In the current fully analytical computational scheme, it is hypothesized that the composite nonlinear behavior can be characterized using two scalar variables that are related to the matrix equivalent strain. This idea is similar to the mean-field theories in which the average value of the strain fields are utilized to determine the matrix nonlinear progression. ${ }^{6,9,10}$ As a result, these two scalar variables are defined based upon the maximum and average value of the square of the matrix equivalent strain at the fiber-matrix interface, respectively, as,

$$
\begin{aligned}
& V_{\text {max }}=\max \left\{\frac{1}{2}\left[\left(\bar{\epsilon}_{11}^{m}-\bar{\epsilon}_{22}^{m}\right)^{2}+\left(\bar{\epsilon}_{22}^{m}-\bar{\epsilon}_{33}^{m}\right)^{2}+\left(\bar{\epsilon}_{33}^{m}-\bar{\epsilon}_{11}^{m}\right)^{2}\right]+\frac{3}{4}\left(\bar{\gamma}_{12}^{m^{2}}+\bar{\gamma}_{13}^{m^{2}}+\bar{\gamma}_{23}^{m^{2}}\right)\right\} \\
& V_{\text {avg }}=\operatorname{avg}\left\{\frac{1}{2}\left[\left(\bar{\epsilon}_{11}^{m}-\bar{\epsilon}_{22}^{m}\right)^{2}+\left(\bar{\epsilon}_{22}^{m}-\bar{\epsilon}_{33}^{m}\right)^{2}+\left(\bar{\epsilon}_{33}^{m}-\bar{\epsilon}_{11}^{m}\right)^{2}\right]+\frac{3}{4}\left(\bar{\gamma}_{12}^{m^{2}}+\bar{\gamma}_{13}^{m^{2}}+\bar{\gamma}_{23}^{m^{2}}\right)\right\}
\end{aligned}
$$

where $\bar{\epsilon}_{i j}^{m}$ 's are the matrix strains at the fiber-matrix interface. Physically, the average term is dominant in the matrix strain field when the fiber volume fraction is low, while the maximum value dominates the result for high fiber volume fractions. Therefore, a weighted function of $V_{\max }$ and $V_{\text {avg }}$ can be written as,

$$
V_{\text {weight }}=V_{f}^{n} V_{\max }+\left(1-V_{f}^{n}\right) V_{\text {avg }}
$$

where $n$ is dependent on the fiber-to-matrix stiffness ratio as,

$$
n=2 \sqrt{\left(\frac{E^{m}}{E_{2}^{f}}+\frac{G^{m}}{G_{23}^{f}}\right)}
$$

Consequently, two matrix equivalent strains can be computed; one is based upon the weight function in Eq. 11, while the other is based upon the average value in Eq. (10), as,

$$
\epsilon_{m, 1}^{e q}=\frac{1}{1+\nu_{s}} \sqrt{V_{w e i g h t}} \quad \text { and } \quad \epsilon_{m, 2}^{e q}=\frac{1}{1+\nu_{s}} \sqrt{V_{a v g}}
$$

In the present study, since the fiber is significantly stiffer than the matrix material, it is assumed that $V_{\text {weight }} \approx V_{\max }$. Once the matrix equivalent strain is resolved, the matrix stiffness tensor is degraded as a secant solid based upon the $J_{2}$ deformation theory of plasticity. According to hypothesis proposed by Zhang and Waas, ${ }^{18}$ the matrix secant moduli calculated using $\epsilon_{m, 1}^{e q}$ were subsequently used to compute the lamina effective secant moduli, $E_{1}^{c}, \nu_{12}^{c}, K_{23}^{c}$, and $G_{23}^{c}$ using Eq. (17), (18), (20), and (21), respectively; whereas the matrix secant moduli determined from $\epsilon_{m, 2}^{e q}$ were used to compute $G_{12}^{c}$ using Eq. (19). Consequently, if matrix microdamage occurs, the stiffness of the subscale microstructure is reduced based upon the proposed secant-modulus approach. The subscale stiffness tensors were subsequently used to update the lamina stiffness and stresses in the full 3D FE model. 


\section{III.C. Lamina Failure Mechanisms: Post-Peak Strain Softening Response}

Since the lamina pre-peak nonlinear response is attributed to matrix microdamage, no macroscopic damage criterion is required to drive the nonlinear damage progression. However, multiple catastrophic failure modes were observed in the experiment, including $0^{\circ}$ tensile failure due to fiber breakage, $0^{\circ}$ compressive failure due to kinking, and failure due to matrix cracking in $90^{\circ}$ (transverse) tests, as schematically shown in Figure 3. These modes of failure result in a loss of load-carrying capability of composite structure, followed by a post-peak strain softening response. Since the positive definiteness of the material tangent stiffness matrix is lost in softening regime, the FEA will provide mesh dependent results if no characteristic length is introduced..$^{25,26}$ As a result, the aforementioned two-scale model has to be supplemented by a suitable mesh objective approach for modeling the post-peak softening response.

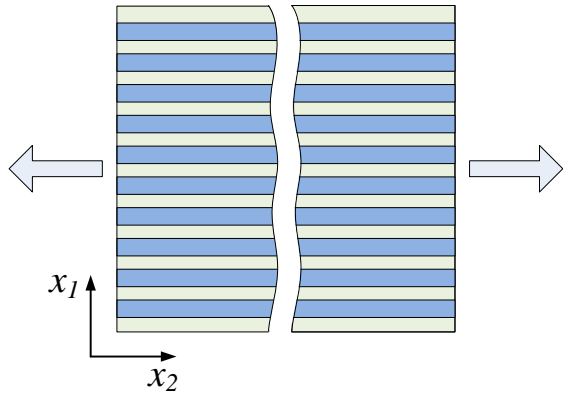

(a) $0^{\circ}$ tensile failure.

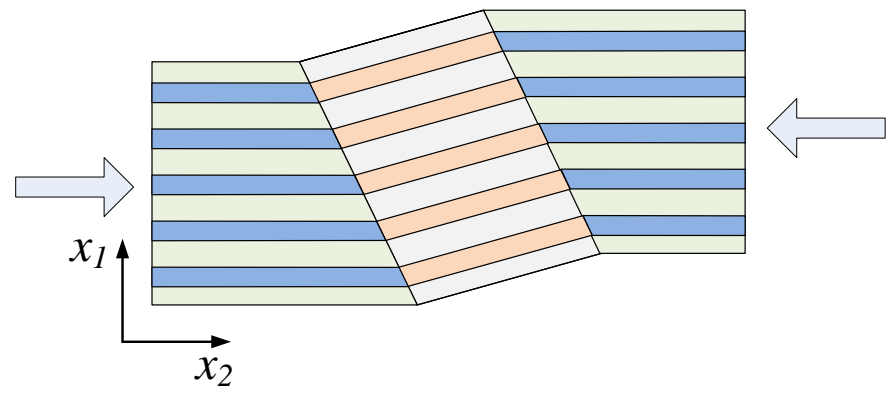

(b) $0^{\circ}$ compressive failure.

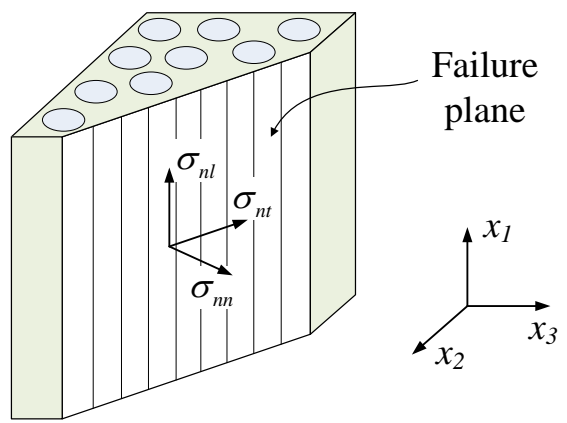

(c) Transverse matrix cracking.

Figure 3. Various failure modes.

Rather than modeling the failure evolution through micromechanical analysis, ${ }^{14,27,28,29}$ phenomenological failure criteria have been employed in the past by assuming the existence of certain types of failure modes. This work was pioneered by Hashin, ${ }^{30}$ and was later improved and implemented within a FE framework by a number of researchers ${ }^{31,32,33,34}$ to demonstrate the predictive capability of this methodology. The use of phenomenological failure criteria offers distinct computational efficiency compared with the micromechanics model.

In this study, the lamina post-peak failure response at the macroscale was modeled using the smeared crack approach (SCA). This method was proposed by Rots et al. ${ }^{35}$ to model crack propagation and fracture in concrete. In the SCA, it is assumed that distributed cracks are "smeared" out over a certain width within a finite element such that the effect of progressive cracking is represented by a macroscopic strain softening behavior in a continuum scheme, as illustrated in Figure 4. The SCA is an outgrowth of the crack band model of Bazant and $\mathrm{Oh},{ }^{25}$ which has been successfully used for capturing post-peak softening, for instance by Pineda et al. ${ }^{36}$ To restore mesh objectivity, a characteristic length is introduced such that the total amount of energy dissipated during failure in a continuum element is equal to the fracture toughness defined for a cohesive element of the same size. The fracture toughness, or the critical energy release rate, $G_{C}$, is defined by the area under the traction-separation law that dictates the cohesive behavior of crack 
propagation (see Figure 4(b)) as,

$$
G_{C}=\int_{0}^{\delta_{f}} \sigma \mathrm{d} u
$$

where $u$ is the sum of crack displacements within the fracture zone, as schematically shown in Figure 4(a). In the SCA, $u$ represents the crack strain acting across a certain width within a finite element, denoted as the crack band width, $h$, which is shown in Figure 4(b). Assuming that all the cracks are uniformly distributed over the crack band, and since $u$ is the accumulation of all the crack strains over the fracture zone, it follows that,

$$
u=h \epsilon^{c r}
$$

If $g_{c}$ represents the area under the softening branch of the stress-strain response, then substituting Eq. (15) into Eq. (14) results in,

$$
G_{C}=\int_{0}^{\delta_{f}} \sigma\left(h \epsilon^{c r}\right) h \mathrm{~d} \epsilon^{c r}=h \int_{0}^{\epsilon_{f}^{c r}} \sigma\left(\epsilon^{c r}\right) \mathrm{d} \epsilon^{c r}=h g_{c}
$$

Therefore, the strain-based description for a softening material is related to the displacement-based tractionseparation laws through the characteristic length, $h$. In a FE setting, $h$ is chosen based upon the element type, element size, element shape, and the integration scheme. ${ }^{35}$

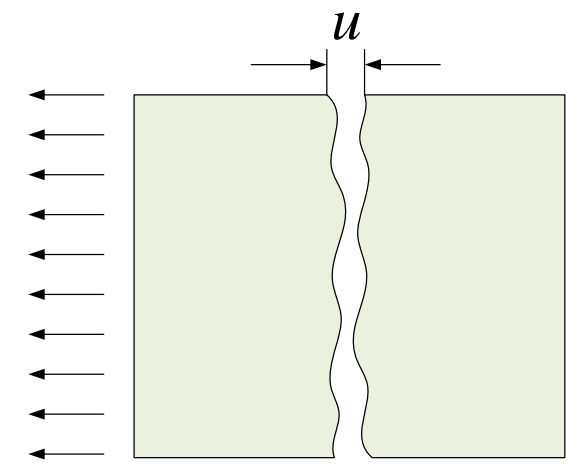

(a) Discrete crack.

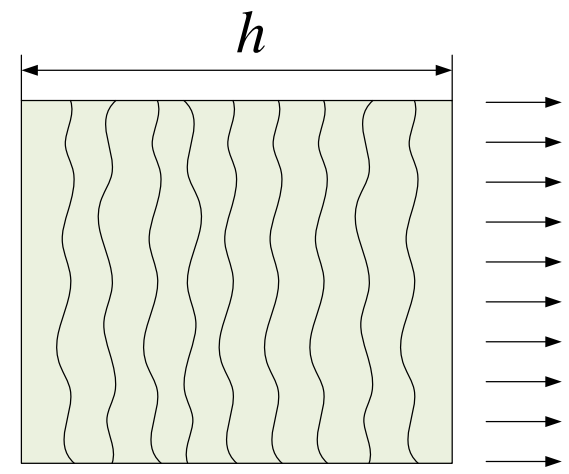

(b) Smeared crack.

Figure 4. Discrete cracks are smeared out within a finite element.

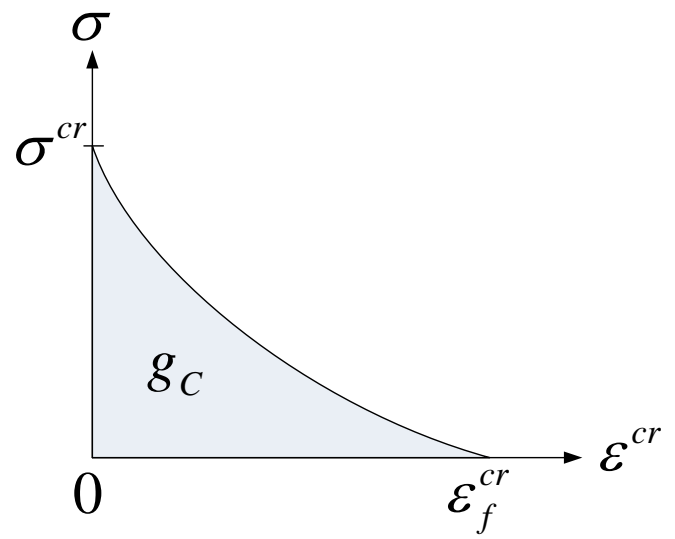

(a) Critical stress-strain curve.

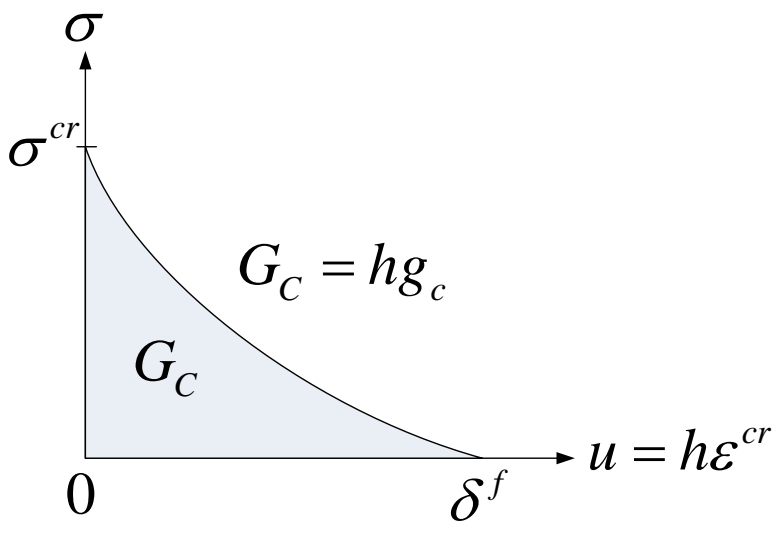

(b) Traction-separation law.

Figure 5. Stress-strain softening response is related to traction-separation law through a characteristic length, $h$.

In the present model, four different failure modes were considered, including tensile and compressive failure in the $0^{\circ}$ and $90^{\circ}$ directions respectively. In addition, when the $0^{\circ}$ failure was initiated in either tension or compression, the crack plane was assumed to be aligned perpendicular to the fiber direction. 
On the other hand, the crack plane was assumed to be parallel to the fiber direction when the $90^{\circ}$ failure criterion was reached. Details of the implementation of the SCA within a FE framework are provided in Refs. ${ }^{37,38,39,40}$ The failure properties, including the critical stress and fracture toughness for each mode of failure, are summarized in Table 5. It is worth noting that the $0^{\circ}$ compressive strength measured in the experiment (see Table 1) is significantly lower than the value reported in the literature. ${ }^{41}$ This mode of failure is dominant by fiber kinking, which can be predicted using the numerical model proposed by Davidson et al. ${ }^{42}$ This model was utilized to determine the $0^{\circ}$ compressive strength used in the subsequent analysis by assuming a fiber misalignment angle of $1^{\circ}$.

Table 5. Failure properties used in the SCA model.

\begin{tabular}{lcc}
\hline Failure mode & $\sigma_{c r}(\mathrm{MPa})$ & $G_{c}(\mathrm{~N} / \mathrm{mm})$ \\
\hline $0^{\circ}$ tension & 2905 & 40 \\
$0^{\circ}$ compression & 1680 & 10 \\
\hline $90^{\circ}$ tension & 44.4 & 2 \\
$90^{\circ}$ compression & 247.3 & 2 \\
\hline
\end{tabular}

\section{Results and Discussion}

The predicted stiffness and strength of the three different laminates are compared against the experimental results for both un-notched and open-hole specimens subjected to tension and compression, as summarized in Table 6. The progressive damage and failure responses of each laminate subjected to un-notched tension, un-notched compression, open-hole tension, and open-hole compression are shown in Figure 6, 7, 8, and 9, respectively. In these figures, only one representative experimental curve is plotted for each loading case, along with the confidence bounds that were provided by the AFRL.

Overall, the proposed model shows a good prediction for the elastic stiffness of each case. The tensile stiffnesses for both un-notched and open-hole specimens were overpredicted, while the maximum error was less than $6 \%$. In the compressive tests, the proposed model overpreicted the stiffness for all the un-notched specimens, while the results for open-hole specimens showed an underprediction. Such results indicate that the presence of an open hole can introduce local strain concentrations that affect the strain histories. It is also worth noting that the open-hole specimens used in tensile and compressive tests have different dimensions. Thus, in order to improve the prediction, it is important to investigate the local fields induced by the hole.

Compared with the stiffness predictions, the strength predictions showed more variations for the 12 different cases. The model accurately predicted the tensile strengths for all the un-notched specimens, however, the strengths were underpredicted for the open-hole specimens with the $[60 / 0-60]_{3 s}$ and $[30 / 60 / 90 /-60 /-30]_{2 s}$ lay-ups. The worst prediction of compressive strengths occurred in the $[60 / 0-60]_{3 s}$ lay-up, which shows an underprediction of about $17 \%$ for both un-notched and open-hole specimens, but still within the confidence bounds indicated in the figure. Nevertheless, the proposed model demonstrates a good predictive capability for strength predictions since the same model has been used for both compressive and tensile failure predictions. 
Table 6. Stiffness and strength predictions of the three different laminates.

\begin{tabular}{|c|c|c|c|c|c|c|c|}
\hline & \multicolumn{3}{|c|}{ Stiffness } & \multicolumn{3}{|c|}{ Strength } \\
\hline & & $\begin{array}{c}\text { Experiment } \\
(\mathrm{GPa})\end{array}$ & $\begin{array}{c}\text { Prediction } \\
(\mathrm{GPa})\end{array}$ & \%error & $\begin{array}{c}\text { Experiment } \\
(\mathrm{MPa})\end{array}$ & $\begin{array}{c}\text { Prediction } \\
(\mathrm{MPa})\end{array}$ & \%error \\
\hline \multirow{3}{*}{$\begin{array}{l}\text { Un-notched } \\
\text { tension }\end{array}$} & \multirow{3}{*}{$\begin{array}{c}{[0 / 45 / 90 /-45]_{2 s}} \\
{[60 / 0 /-60]_{3 s}} \\
{[30 / 60 / 90 /-60 /-30]_{2 s}}\end{array}$} & 60.5 & 60.6 & $0.18 \%$ & 866 & 856 & $-1.16 \%$ \\
\hline & & 59.5 & 61.5 & $3.34 \%$ & 1005 & 1010 & $0.47 \%$ \\
\hline & & 38.0 & 39.7 & $4.34 \%$ & 473 & 462 & $-2.36 \%$ \\
\hline \multirow{3}{*}{$\begin{array}{l}\text { Un-notched } \\
\text { compression }\end{array}$} & \multirow{3}{*}{$\begin{array}{c}{[0 / 45 / 90 /-45]_{2 s}} \\
{[60 / 0 /-60]_{3 s}} \\
{[30 / 60 / 90 /-60 /-30]_{2 s}} \\
\end{array}$} & 48.0 & 52.7 & $9.89 \%$ & 603 & 634 & $5.14 \%$ \\
\hline & & 48.9 & 52.3 & $7.02 \%$ & 765 & 632 & $-17.44 \%$ \\
\hline & & 33.5 & 34.7 & $3.63 \%$ & 382 & 428 & $12.04 \%$ \\
\hline \multirow{3}{*}{$\begin{array}{c}\text { Open-hole } \\
\text { tension }\end{array}$} & \multirow{3}{*}{$\begin{array}{c}{[0 / 45 / 90 /-45]_{2 s}} \\
{[60 / 0 /-60]_{3 s}} \\
{[30 / 60 / 90 /-60 /-30]_{2 s}}\end{array}$} & 48.3 & 50.3 & $4.13 \%$ & 554 & 557 & $0.54 \%$ \\
\hline & & 48.8 & 50.9 & $4.27 \%$ & 543 & 502 & $-7.55 \%$ \\
\hline & & 32.4 & 34.4 & $6.09 \%$ & 409 & 373 & $-8.80 \%$ \\
\hline \multirow{3}{*}{$\begin{array}{l}\text { Open-hole } \\
\text { compression }\end{array}$} & \multirow{3}{*}{$\begin{array}{c}{[0 / 45 / 90 /-45]_{2 s}} \\
{[60 / 0 /-60]_{3 s}} \\
{[30 / 60 / 90 /-60 /-30]_{2 s}}\end{array}$} & 44.5 & 41.8 & $-5.98 \%$ & 341 & 341 & $0.00 \%$ \\
\hline & & 44.4 & 41.9 & $-5.69 \%$ & 358 & 299 & $-16.48 \%$ \\
\hline & & 30.1 & 29.8 & $-1.12 \%$ & 295 & 304 & $3.05 \%$ \\
\hline
\end{tabular}

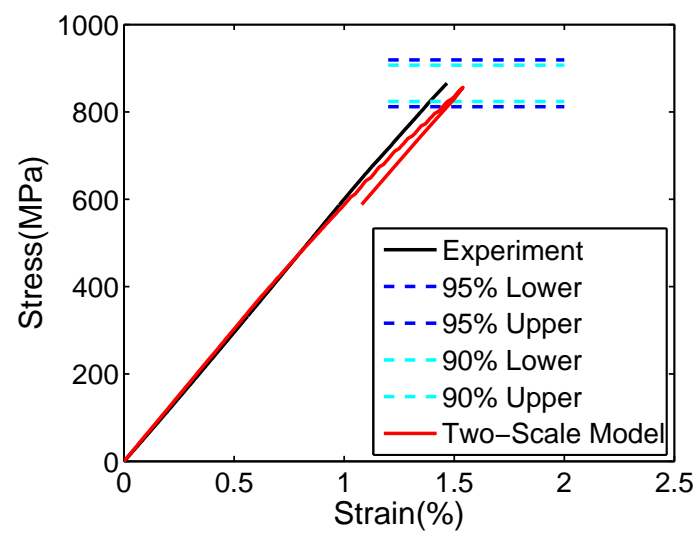

(a) $(0 / 45 / 90 /-45)_{2 s}$.

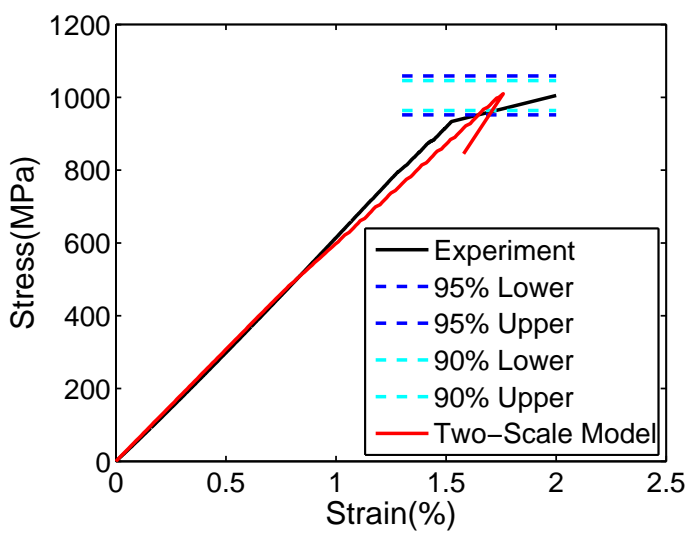

(b) $(60 / 0 /-60)_{3 s}$.

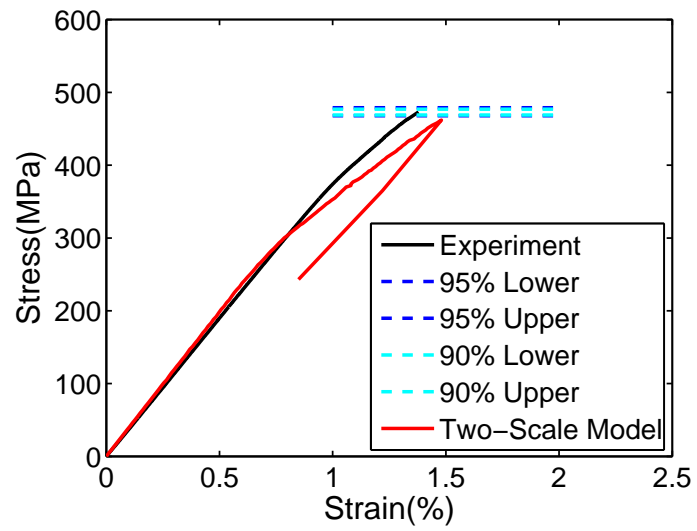

(c) $(30 / 60 / 90 /-60 /-30)_{2 s}$.

Figure 6. Comparison of the stress-strain responses obtained from the present two-scale model and the experiment for each laminate subjected to un-notched tension. 


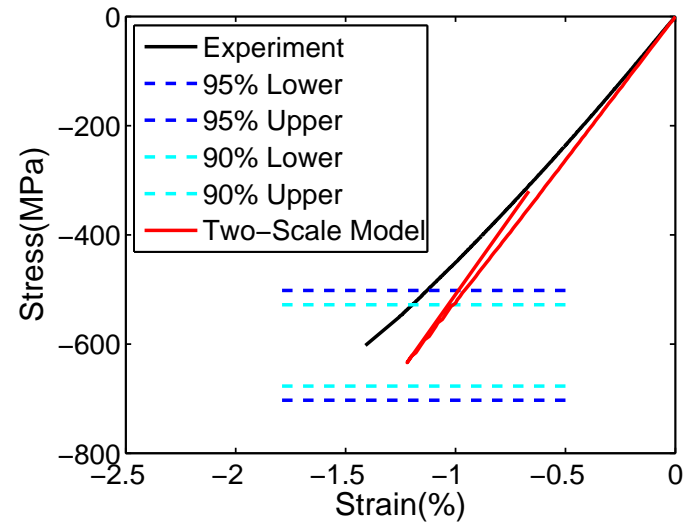

(a) $(0 / 45 / 90 /-45)_{2 s}$

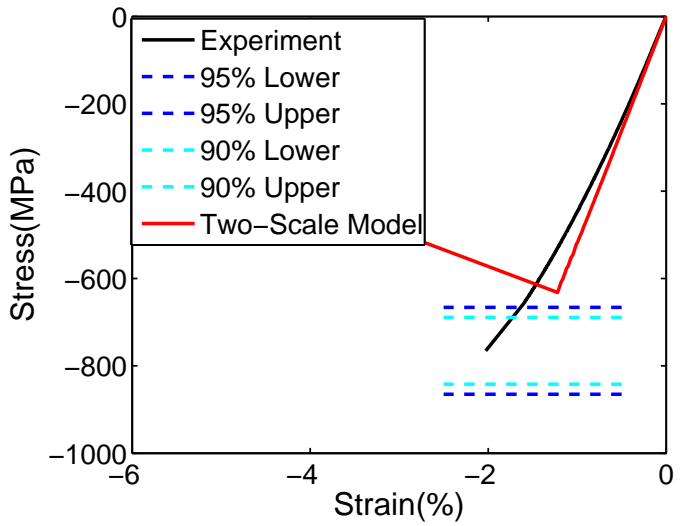

(b) $(60 / 0 /-60)_{3 s}$

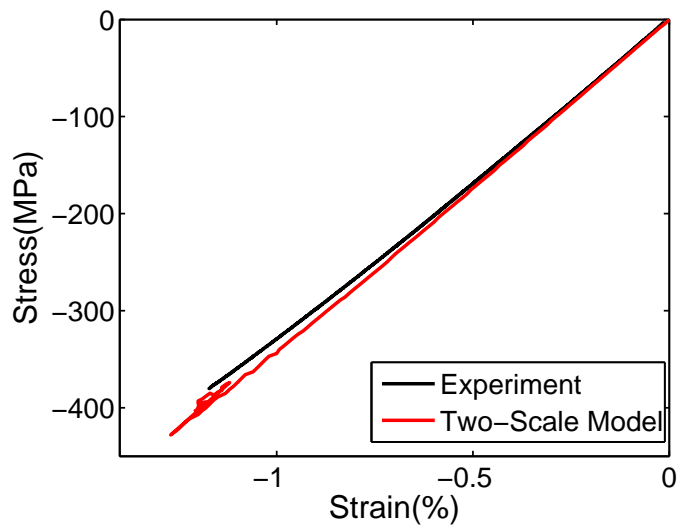

(c) $(30 / 60 / 90 /-60 /-30)_{2 s}$

Figure 7. Comparison of the stress-strain responses obtained from the present two-scale model and the experiment for each laminate subjected to un-notched compression. 


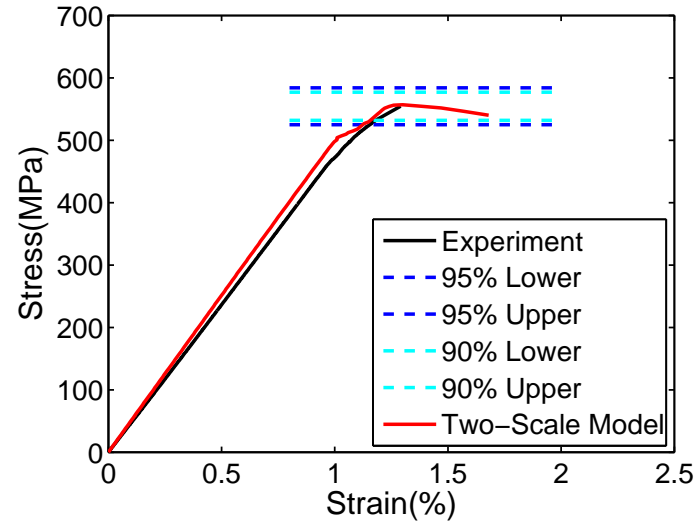

(a) $(0 / 45 / 90 /-45)_{2 s}$

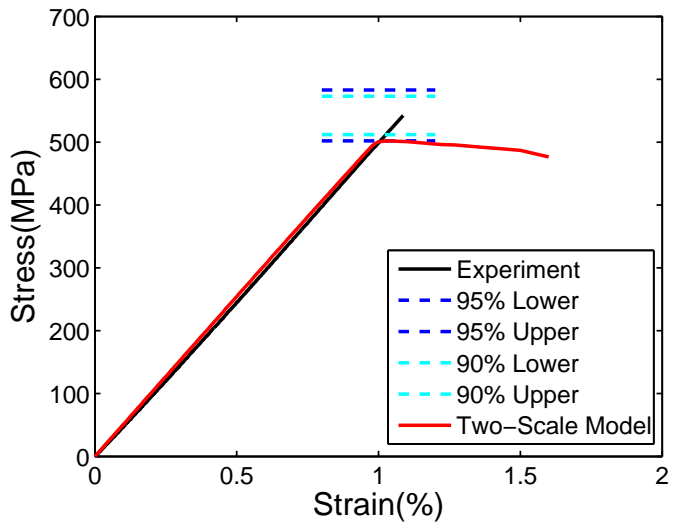

(b) $(60 / 0 /-60)_{3 \mathrm{~s}}$

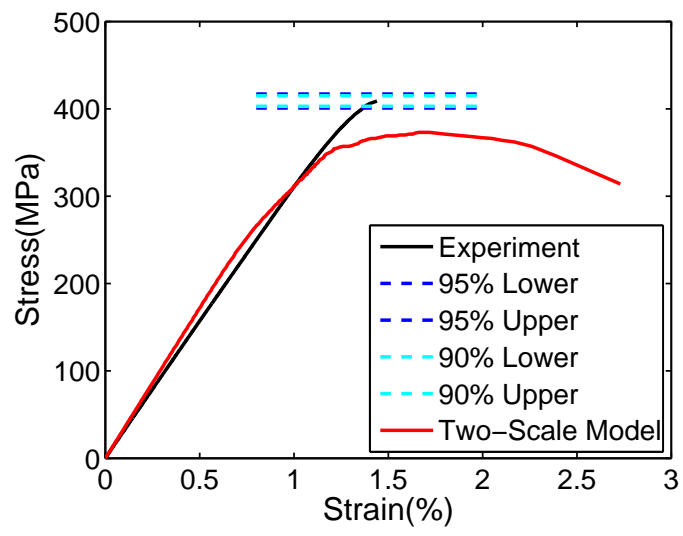

(c) $(30 / 60 / 90 /-60 /-30)_{2 s}$

Figure 8. Comparison of the stress-strain responses obtained from the present two-scale model and the experiment for each laminate subjected to open-hole tension. 


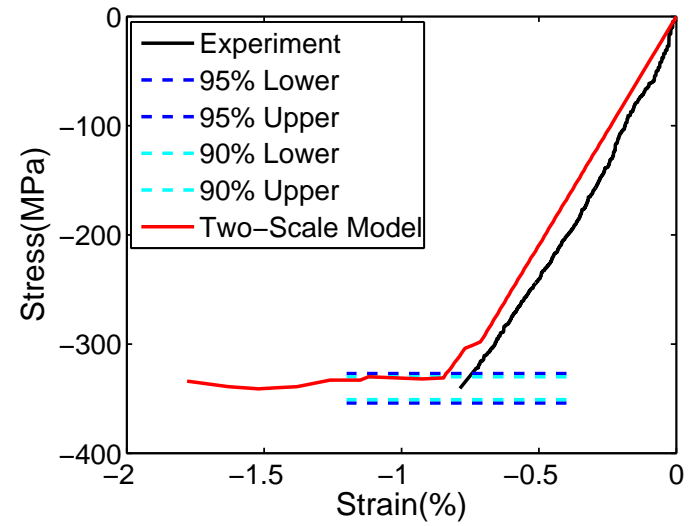

(a) $(0 / 45 / 90 /-45)_{2 s}$

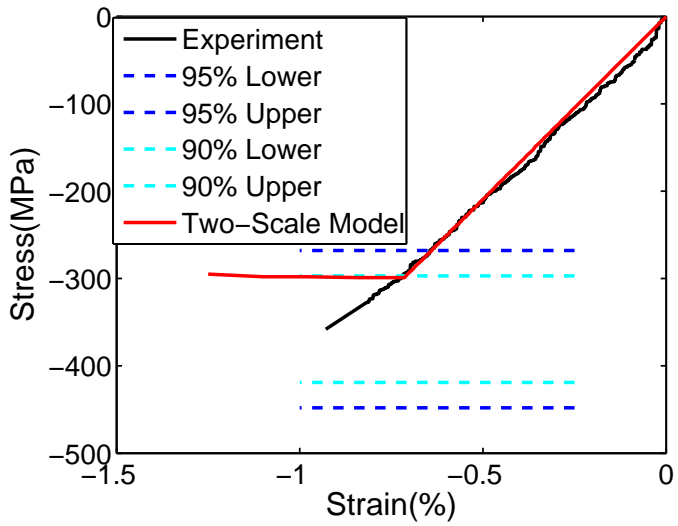

(b) $(60 / 0 /-60)_{3 s}$

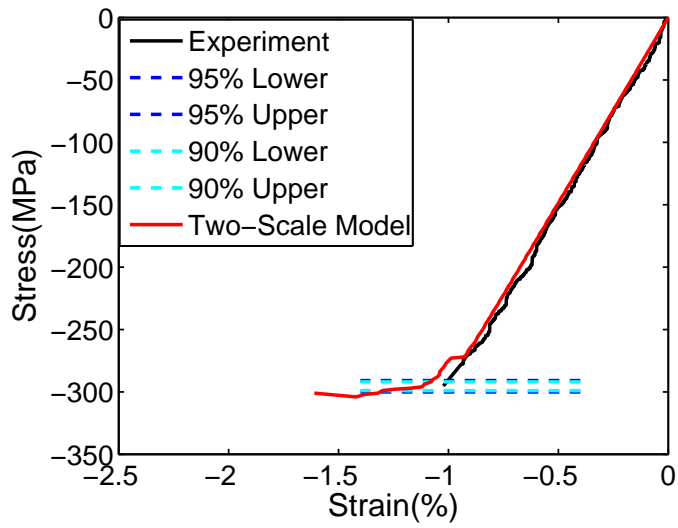

(c) $(30 / 60 / 90 /-60 /-30)_{2 s}$

Figure 9. Comparison of the stress-strain responses obtained from the present two-scale model and the experiment for each laminate subjected to open-hole compression. 


\section{Conclusions}

A two-scale, micromechanics-based computational scheme was developed to predict the progressive damage and failure responses of composite laminate using the constituent properties measured from lamina-level coupon tests. In the proposed computational scheme, each lamina was homogenized as a 3D solid at the macroscale, while a novel micromechanics model was implemented at each integration point to capture the evolution of matrix microdamage and compute the lamina stiffness. The lamina post-peak strain softening response resulting from catastrophic failure modes including fiber tensile breakage, fiber kinking and matrix cracking, were modeled using the SCA. The interlaminar failure due to delamination is accounted for through cohesive elements inserted in-between the layers. Using the constituent properties measured from IM-7/977-3 lamina as inputs, the proposed model demonstrates a good predictive capability for the progressive damage and failure responses of three different lay-ups of the same composite system. Since fully analytical solutions are utilized for the micromechanical analysis, the proposed method offers a distinct computational advantage in a multiscale analysis and is therefore suitable for large-scale progressive damage and failure analyses of laminated structures. Work is continuing to study the effect of mesh size on the resulting predictions.

\section{Acknowledgments}

The authors are grateful for useful discussions with Steven P. Engelstad (Lockheed-Martin), Steven M. Arnold, Brett Bednarcyk and Evan Pineda (NASA-Glenn), and Bertram Stier, visiting student from Aachen University, Germany. We acknowledge the sponsorship of the Air Force Research Laboratory (AFRL) through Lockheed-Martin, and the support of Steve Clay (AFRL).

\section{References}

${ }^{1}$ Herakovich, C. T., Mechanics of Fibrous Composites, John Wiley \& Sons, Inc., 1998.

${ }^{2}$ Aboudi, J., Arnold, S. M., and Bednarcyk, B. A., Micromechanics of Composite Materials: A Generalized Multiscale Analysis Approach, Elsevier, 1st ed., 2013.

${ }^{3}$ Prabhakar, P. and Waas, A. M., "Upscaling from a micro-mechanics model to capture laminate compressive strength due to kink banding instability," Computational Materials Science, Vol. 67, 2013, pp. 40-47. doi:10.1016/j.commatsci.2012.08.025.

${ }^{4}$ Zhao, Y. H. and Weng, G. J., "Theory of plasticity for a class of inclusion and fiber-reinforced composites," $M i$ cromechanics and Inhomogeneity, edited by G. Weng, M. Taya, and H. Abé, Springer, New York, 1990, pp. 599-622. doi:10.1007/978-1-4613-8919-4_37.

${ }^{5}$ Qiu, Y. P. and Weng, G. J., "A theory of plasticity for porous materials and particle-reinforced composites," Journal of Applied Mechanics, Vol. 59, No. 2, 1992, pp. 261-268. doi:10.1115/1.2899515.

${ }^{6}$ Segurado, J., Llorca, J., and González, C., "On the accuracy of mean-field approaches to simulate the plastic deformation of composites," Scripta Materialia, Vol. 46, No. 7, 2002, pp. 525-529. doi:10.1016/S1359-6462(02)00027-1.

${ }^{7}$ Nemat-Nasser, S., Iwakuma, T., and Hejazi, M., "On composites with periodic structure," Mechanics of Materials, Vol. 1, No. 3, Sept. 1982, pp. 239-267. doi:10.1016/0167-6636(82)90017-5.

${ }^{8}$ Dvorak, G. J. and Benveniste, Y., "On transformation strains and uniform fields in multiphase elastic media," Proceedings: Mathematical and Physical Sciences, Vol. 437, No. 1900, 1992, pp. 291-310.

${ }^{9}$ Dvorak, G. J., "Transformation field analysis of inelastic composite materials," Proceedings: Mathematical and Physical Sciences, Vol. 437, No. 1900, 1992, pp. 311-327.

${ }^{10}$ Michel, J. and Suquet, P., "Nonuniform transformation field analysis," International Journal of Solids and Structures, Vol. 40, No. 25, Dec. 2003, pp. 6937-6955. doi:10.1016/S0020-7683(03)00346-9.

${ }^{11}$ Aboudi, J., Mechanics of Composite Materials: A Unified Micromechanical Approach, Elsevier, Amsterdam, 1991.

${ }^{12}$ Paley, M. and Aboudi, J., "Micromechanical analysis of composites by the generalized cells model," Mechanics of Materials, Vol. 14, No. 2, Dec. 1992, pp. 127-139. doi:10.1016/0167-6636(92)90010-B.

${ }^{13}$ Aboudi, J., Pindera, M.-J., and Arnold, S. M., "Linear thermoelastic higher-order theory for periodic multiphase materials," Journal of Applied Mechanics, Vol. 68, No. 5, 2001, pp. 697-707. doi:10.1115/1.1381005.

${ }^{14}$ Pineda, E. J., Bednarcyk, B. A., Waas, A. M., and Arnold, S. M., "Progressive failure of a unidirectional fiber-reinforced composite using the method of cells: Discretization objective computational results," International Journal of Solids and Structures, Vol. 50, No. 9, May 2013, pp. 1203-1216. doi:10.1016/j.ijsolstr.2012.12.003.

${ }^{15}$ Bednarcyk, B. A., Arnold, S. M., Aboudi, J., and Pindera, M.-J., "Local field effects in titanium matrix composites subject to fiber-matrix debonding," International Journal of Plasticity, Vol. 20, No. 8-9, Aug. 2004, pp. 1707-1737. doi:10.1016/j.ijplas.2003.11.019.

${ }^{16}$ Bednarcyk, B. A., Aboudi, J., and Arnold, S. M., "Micromechanics modeling of composites subjected to multiaxial progressive damage in the constituents," AIAA Journal, Vol. 48, No. 7, July 2010, pp. 1367-1378. doi:10.2514/1.45671.

${ }^{17} \mathrm{Haj}-\mathrm{Ali}, \mathrm{R}$. and Aboudi, J., "Formulation of the high-fidelity generalized method of cells with arbitrary cell geometry for refined micromechanics and damage in composites," International Journal of Solids and Structures, Vol. 47, No. 25-26, Dec. 2010, pp. 3447-3461. doi:10.1016/j.ijsolstr.2010.08.022. 
${ }^{18}$ Zhang, D. and Waas, A., "A micromechanics based multiscale model for nonlinear composites," Acta Mechanica, Vol. 225, No. 4-5, 2014, pp. 1391-1417. doi:10.1007/s00707-013-1057-1.

${ }^{19}$ Yerramalli, C. S. and Waas, A. M., "In situ matrix shear response using torsional test data of fiber reinforced unidirectional polymer composites," Journal of Engineering Materials and Technology, Vol. 124, No. 2, 2002, pp. 152. doi:10.1115/1.1446471.

${ }^{20}$ Song, S., Waas, A. M., Shahwan, K. W., Faruque, O., and Xiao, X. S., "Compression response, strength and post-peak response of an axial fiber reinforced tow," International Journal of Mechanical Sciences, Vol. 51, No. 7, July 2009, pp. $491-499$. doi:10.1016/j.ijmecsci.2009.03.008.

${ }^{21} \mathrm{Ng}$, W. H., Salvi, A. G., and Waas, A. M., "Characterization of the in-situ non-linear shear response of laminated fiberreinforced composites," Composites Science and Technology, Vol. 70, No. 7, July 2010, pp. 1126-1134. doi:10.1016/j.compscitech.2010.02.024.

${ }^{22}$ Benzeggagh, M. and Kenane, M., "Measurement of mixed-mode delamination fracture toughness of unidirectional glass/epoxy composites with mixed-mode bending apparatus," Composites Science and Technology, Vol. 56, No. 4, Jan. 1996, pp. 439-449. doi:10.1016/0266-3538(96)00005-X.

${ }^{23}$ Hashin, Z. and Rosen, B. W., "The elastic moduli of fiber-reinforced materials," Journal of Applied Mechanics, Vol. 31, No. 2, 1964, pp. 223-232. doi:10.1115/1.3629590.

${ }^{24}$ Christensen, R. and Lo, K., "Solutions for effective shear properties in three phase sphere and cylinder models," Journal of the Mechanics and Physics of Solids, Vol. 27, No. 4, 1979, pp. 315-330. doi:10.1016/0022-5096(79)90032-2.

${ }^{25}$ Bažant, Z. P. and Oh, B. H., "Crack band theory for fracture of concrete," Matériaux et Constructions, Vol. 16, No. 3, May 1983, pp. 155-177. doi:10.1007/BF02486267.

${ }^{26}$ Bažant, Z. P. and Cedolin, L., Stability of Structures: Elastic, Inelastic, Fracture, and Damage Theories, Oxford University Press, Inc., 1991.

${ }^{27}$ Totry, E., González, C., and LLorca, J., "Influence of the loading path on the strength of fiber-reinforced composites subjected to transverse compression and shear," International Journal of Solids and Structures, Vol. 45, No. 6, March 2008, pp. 1663-1675. doi:10.1016/j.ijsolstr.2007.10.014.

${ }^{28}$ Totry, E., González, C., and LLorca, J., "Prediction of the failure locus of C/PEEK composites under transverse compression and longitudinal shear through computational micromechanics," Composites Science and Technology, Vol. 68, No. 15-16, Dec. 2008, pp. 3128-3136. doi:10.1016/j.compscitech.2008.07.011.

${ }^{29}$ Totry, E., Molina-Aldareguía, J. M., González, C., and LLorca, J., "Effect of fiber, matrix and interface properties on the in-plane shear deformation of carbon-fiber reinforced composites," Composites Science and Technology, Vol. 70, No. 6, June 2010, pp. 970-980. doi:10.1016/j.compscitech.2010.02.014.

${ }^{30}$ Hashin, Z., "Failure Criteria for Unidirectional Fiber Composites," Journal of Applied Mechanics, Vol. 47, No. 2, 1980, pp. 329. doi:10.1115/1.3153664.

${ }^{31}$ Puck, A., "Failure analysis of FRP laminates by means of physically based phenomenological models," Composites Science and Technology, Vol. 58, No. 7, July 1998, pp. 1045-1067. doi:10.1016/S0266-3538(96)00140-6.

${ }^{32}$ Puck, A. and Schürmann, H., "Failure analysis of FRP laminates by means of physically based phenomenological models," Composites Science and Technology, Vol. 62, No. 12-13, Sept. 2002, pp. 1633-1662. doi:10.1016/S0266-3538(01)00208-1.

${ }^{33}$ Camanho, P. P., Dávila, C. G., Pinho, S. T., Iannucci, L., and Robinson, P., "Prediction of in situ strengths and matrix cracking in composites under transverse tension and in-plane shear," Composites Part A: Applied Science and Manufacturing, Vol. 37, No. 2, Feb. 2006, pp. 165-176. doi:10.1016/j.compositesa.2005.04.023.

${ }^{34}$ Camanho, P., Maimí, P., and Dávila, C., "Prediction of size effects in notched laminates using continuum damage mechanics," Composites Science and Technology, Vol. 67, No. 13, Oct. 2007, pp. 2715-2727. doi:10.1016/j.compscitech.2007.02.005.

${ }^{35}$ Rots, G., Nauta, P., Kusters, G. M. A., and Blaauwendraad, J., "Smeared crack approach and fracture localization in concrete," HERON, Vol. 30, No. 1, 1985, pp. 1-48.

${ }^{36}$ Pineda, E. J. and Waas, A. M., "Numerical implementation of a multiple-ISV thermodynamically-based work potential theory for modeling progressive damage and failure in fiber-reinforced laminates," International Journal of Fracture, Vol. 182, No. 1, 2013, pp. 93-122. doi:10.1007/s10704-013-9860-1.

${ }^{37}$ Heinrich, C. and Waas, A., "Investigation of progressive damage and fracture in laminated composites using the smeared crack approach," 53rd AIAA/ASME/ASCE/AHS/ASC Structures, Structural Dynamics and Materials Conference, Honolulu, Hawaii, April 2012, AIAA 2012-1537.

${ }^{38}$ Heinrich, C. and Waas, A. M., "Investigation of progressive damage and fracture in laminated composites using the smeared crack approach," CMC: Computers, Materials \& Continua, Vol. 35, No. 2, 2013, pp. $155-181$. doi:10.3970/cmc.2013.035.155.

${ }^{39}$ Zhang, D., Waas, A. M., and Yen, C., "Progressive failure analysis on textile composites," AIAA SciTech, 55rd AIAA/ASME/ASCE/AHS/ASC Structures, Structural Dynamics and Materials Conference, National Harbor, Maryland, January 2014, AIAA 2014-0157.

${ }^{40}$ Zhang, D., Progressive Damage and Failure Analysis of 3D Textile Composites Subjected to Flexural Loading, Ph.D. thesis, University of Michigan, 2014.

${ }^{41}$ Hexcel, "HexTow IM7 Carbon Fiber," 2010, http://www.hexcel.com/resources/datasheets/carbon-fiber-data-sheets/im7. pdf.

${ }^{42}$ Davidson, P., Pineda, E. J., Heinrich, C., and Waas, A. M., "A unified model for predicting the open hole tensile and compressive strengths of composite laminates for aerospace applications," 54th AIAA/ASME/ASCE/AHS/ASC Structures, Structural Dynamics and Materials Conference, Boston, Massachusetts, April 8-11 2013, AIAA 2013-1613. 


\section{Appendix}

\section{A. Computation of the Tow Effective Properties}

The five effective fiber tow constants defined in Section III.B.1 are computed based upon the fiber and matrix properties as,

$$
\begin{aligned}
E_{1}^{t} & =E_{1}^{f} V_{f}+E^{m}\left(1-V_{f}\right)+\frac{4 V_{f}\left(1-V_{f}\right)\left(\nu_{12}^{f}-\nu^{m}\right)^{2} G^{m}}{\frac{G^{m}\left(1-V_{f}\right)}{K_{23}^{f}}+\frac{G^{m} V_{f}}{K_{23}^{m}}+1} \\
\nu_{12}^{t} & =\nu_{12}^{f} V_{f}+\nu^{m}\left(1-V_{f}\right)+\frac{V_{f}\left(1-V_{f}\right)\left(\nu_{12}^{f}-\nu^{m}\right)\left(\frac{G^{m}}{K_{23}^{m}}-\frac{G^{m}}{K_{23}^{f}}\right)}{\frac{G^{m}\left(1-V_{f}\right)}{K_{23}^{f}}+\frac{G^{m} V_{f}}{K_{23}^{m}}+1} \\
G_{12}^{t} & =G^{m} \frac{G_{12}^{f}\left(1+V_{f}\right)+G^{m}\left(1-V_{f}\right)}{G_{12}^{f}\left(1-V_{f}\right)+G^{m}\left(1+V_{f}\right)} \\
K_{23}^{t} & =K_{23}^{m}+\frac{V_{f}}{\frac{1}{K_{23}^{f}-K_{23}^{m}}+\frac{1-V_{f}}{K_{23}^{m}+G^{m}}}
\end{aligned}
$$

$G_{23}^{t}$ is computed through a quadratic equation as,

$$
A\left(\frac{G_{23}^{c}}{G^{m}}\right)^{2}+B\left(\frac{G_{23}^{t}}{G^{m}}\right)+C=0
$$

where,

$$
\begin{aligned}
& A=a_{0}+a_{1} V_{f}+a_{2} V_{f}^{2}+a_{3} V_{f}^{3}+a_{4} V_{f}^{4} \\
& B=b_{0}+b_{1} V_{f}+b_{2} V_{f}^{2}+b_{3} V_{f}^{3}+b_{4} V_{f}^{4} \\
& C=c_{0}+c_{1} V_{f}+c_{2} V_{f}^{2}+c_{3} V_{f}^{3}+c_{4} V_{f}^{4}
\end{aligned}
$$

with,

$$
\begin{aligned}
& a_{0}=-2 G^{m^{2}}\left(2 G^{m}+K_{23}^{m}\right)\left[2 G_{23}^{f} G^{m}+K_{23}^{f}\left(G_{23}^{f}+G^{m}\right)\right]\left[2 G_{23}^{f} G^{m}+K_{23}^{m}\left(G_{23}^{f}+G^{m}\right)\right] \\
& a_{1}=8 G^{m^{2}}\left(G_{23}^{f}-G^{m}\right)\left[2 G_{23}^{f} G^{m}+K_{23}^{f}\left(G_{23}^{f}+G^{m}\right)\right]\left(G^{m^{2}}+G^{m} K_{23}^{m}+K_{23}^{m^{2}}\right) \\
& a_{2}=-12 G^{m^{2}} K_{23}^{m^{2}}\left(G_{23}^{f}-G^{m}\right)\left[2 G_{23}^{f} G^{m}+K_{23}^{f}\left(G_{23}^{f}+G^{m}\right)\right] \\
& a_{3}=8 G^{m^{2}}\left\{G_{23}^{f^{2}} G^{m^{2}} K_{23}^{f}+G_{23}^{f^{2}} G^{m} K_{23}^{m}\left(K_{23}^{f}-G^{m}\right)+K_{23}^{m^{2}}\left[G_{23}^{f} G^{m}\left(G_{23}^{f}-2 G^{m}\right)+\right.\right. \\
& \left.\left.K_{23}^{f}\left(G_{23}^{f}-G^{m}\right)\left(G_{23}^{f}+G^{m}\right)\right]\right\} \\
& a_{4}=2 G^{m^{2}}\left(G_{23}^{f}-G^{m}\right)\left(2 G^{m}+K_{23}^{m}\right)\left[K_{23}^{f} G^{m} K_{23}^{m}-G_{23}^{f}\left(2 G^{m}\left(K_{23}^{f}-K_{23}^{m}\right)+K_{23}^{f} K_{23}^{m}\right)\right] \\
& b_{0}=4 G^{m^{3}}\left[2 G_{23}^{f} G^{m}+K_{23}^{f}\left(G_{23}^{f}+G^{m}\right)\right]\left[2 G_{23}^{f} G^{m}+K_{23}^{m}\left(G_{23}^{f}+G^{m}\right)\right] \\
& b_{1}=8 G^{m^{2}} K_{23}^{m}\left(G_{23}^{f}-G^{m}\right)\left[2 G_{23}^{f} G^{m}+\left(G_{23}^{f}+G^{m}\right) K_{23}^{f}\right]\left(G^{m}-K_{23}^{m}\right) \\
& b_{2}=-2 a_{2} \\
& b_{3}=-2 a_{3} \\
& b_{4}=-4 G^{m^{3}}\left(G_{23}^{f}-G^{m}\right)\left[K_{23}^{f} G^{m} K_{23}^{m}-G_{23}^{f}\left(2 G^{m}\left(K_{23}^{f}-K_{23}^{m}\right)+K_{23}^{f} K_{23}^{m}\right)\right]
\end{aligned}
$$




$$
\begin{aligned}
& c_{0}=2 G^{m^{2}} K_{23}^{m}\left[2 G_{23}^{f} G^{m}+K_{23}^{f}\left(G_{23}^{f}+G^{m}\right)\right]\left[2 G_{23}^{f} G^{m}+K_{23}^{m}\left(G_{23}^{f}+G^{m}\right)\right] \\
& c_{1}=8 G^{m^{2}} K_{23}^{m^{2}}\left(G_{23}^{f}-G^{m}\right)\left[2 G_{23}^{f} G^{m}+K_{23}^{f}\left(G_{23}^{f}+G^{m}\right)\right] \\
& c_{2}=a_{2} \\
& c_{3}=a_{3} \\
& c_{4}=-2 G^{m^{2}} K_{23}^{m}\left(G_{23}^{f}-G^{m}\right)\left[K_{23}^{f} G^{m} K_{23}^{m}-G_{23}^{f}\left(2 G^{m}\left(K_{23}^{f}-K_{23}^{m}\right)+K_{23}^{f} K_{23}^{m}\right)\right]
\end{aligned}
$$

\section{B. Computation of $F_{i j}$ Components}

The non-zero $F_{i j}$ components in Eq. (8) are computed using the CCM in conjunction with the GSCM, in which the unidirectional composite is represented by an inner fiber core and an outer matrix annulus. The derivation for the $\boldsymbol{F}$ matrix is provided in, ${ }^{18}$ and the results are summarized in Eq. (22)-(26) as,

$$
\begin{aligned}
& F_{11}=1 \\
& F_{21}=\frac{V_{f}\left(\frac{\nu_{12}^{f}}{K_{23}^{m}}-\frac{\nu^{m}}{K_{23}^{f}}\right)}{\frac{V_{f}}{K_{23}^{f}}+\frac{1-2 \nu^{m}}{K_{23}^{f}}+\frac{1-V_{f}}{K_{23}^{m}}}\left[1+\left(\frac{b}{r}\right)^{2} \cos 2 \theta\right] \\
& F_{31}=\frac{V_{f}\left(\frac{\nu_{12}^{f}}{K_{23}^{m}}-\frac{\nu^{m}}{K_{23}^{f}}\right)}{\frac{V_{f}}{K_{23}^{f}}+\frac{1-2 \nu^{m}}{K_{23}^{f}}+\frac{1-V_{f}}{K_{23}^{m}}}\left[1-\left(\frac{b}{r}\right)^{2} \cos 2 \theta\right] \\
& F_{61}=2 \frac{V_{f}\left(\frac{\nu_{12}^{f}}{K_{23}^{m}}-\frac{\nu^{m}}{K_{23}^{f}}\right)}{\frac{V_{f}}{K_{23}^{f}}+\frac{1-2 \nu^{m}}{K_{23}^{f}}+\frac{1-V_{f}}{K_{23}^{m}}}\left(\frac{b}{r}\right)^{2} \sin 2 \theta \\
& F_{22}=\frac{1}{4 G^{m} \bar{\sigma}}\left\{\left[2 K_{23}^{t} \frac{G^{m}}{K_{23}^{m}} N_{2}-G_{23}^{t}\left(2 A_{2}+6 B_{2} \frac{r^{2}}{b^{2}}\right)\right]+\left[K_{23}^{t} M_{2} \frac{b^{2}}{r^{2}}\right.\right. \\
& \left.\left.+2 G_{23}^{t} \frac{G^{m}}{K_{23}^{m}}\left(3 B_{2} \frac{r^{2}}{b^{2}}-D_{2} \frac{b^{2}}{r^{2}}\right)\right] \cos 2 \theta-\left[G_{23}^{t}\left(3 C_{2} \frac{b^{4}}{r^{4}}+2 D_{2} \frac{b^{2}}{r^{2}}\right)\right] \cos 4 \theta\right\} \\
& F_{32}=\frac{1}{4 G^{m} \bar{\sigma}}\left\{\left[2 K_{23}^{t} \frac{G^{m}}{K_{23}^{m}} N_{2}+G_{23}^{t}\left(2 A_{2}+6 B_{2} \frac{r^{2}}{b^{2}}\right)\right]-\left[K_{23}^{t} M_{2} \frac{b^{2}}{r^{2}}\right.\right. \\
& \left.\left.-2 G_{23}^{t} \frac{G^{m}}{K_{23}^{m}}\left(3 B_{2} \frac{r^{2}}{b^{2}}-D_{2} \frac{b^{2}}{r^{2}}\right)\right] \cos 2 \theta+\left[G_{23}^{t}\left(3 C_{2} \frac{b^{4}}{r^{4}}+2 D_{2} \frac{b^{2}}{r^{2}}\right)\right] \cos 4 \theta\right\} \\
& F_{62}=\frac{1}{2 G^{m} \bar{\sigma}}\left[K_{23}^{t} M_{2} \frac{b^{2}}{r^{2}} \sin 2 \theta-G_{23}^{t}\left(3 C_{2} \frac{b^{4}}{r^{4}}+2 D_{2} \frac{b^{2}}{r^{2}}\right) \sin 4 \theta\right]
\end{aligned}
$$




$$
\begin{aligned}
F_{23}= & \frac{1}{4 G^{m} \bar{\sigma}}\left\{\left[2 K_{23}^{t} \frac{G^{m}}{K_{23}^{m}} N_{2}+G_{23}^{t}\left(2 A_{2}+6 B_{2} \frac{r^{2}}{b^{2}}\right)\right]+\left[K_{23}^{t} M_{2} \frac{b^{2}}{r^{2}}\right.\right. \\
& \left.\left.-2 G_{23}^{t} \frac{G^{m}}{K_{23}^{m}}\left(3 B_{2} \frac{r^{2}}{b^{2}}-D_{2} \frac{b^{2}}{r^{2}}\right)\right] \cos 2 \theta+\left[G_{23}^{t}\left(3 C_{2} \frac{b^{4}}{r^{4}}+2 D_{2} \frac{b^{2}}{r^{2}}\right)\right] \cos 4 \theta\right\} \\
F_{33}= & \frac{1}{4 G^{m} \bar{\sigma}}\left\{\left[2 K_{23}^{t} \frac{G^{m}}{K_{23}^{m}} N_{2}-G_{23}^{t}\left(2 A_{2}+6 B_{2} \frac{r^{2}}{b^{2}}\right)\right]-\left[K_{23}^{t} M_{2} \frac{b^{2}}{r^{2}}\right.\right. \\
& \left.\left.+2 G_{23}^{t} \frac{G^{m}}{K_{23}^{m}}\left(3 B_{2} \frac{r^{2}}{b^{2}}-D_{2} \frac{b^{2}}{r^{2}}\right)\right] \cos 2 \theta-\left[G_{23}^{t}\left(3 C_{2} \frac{b^{4}}{r^{4}}+2 D_{2} \frac{b^{2}}{r^{2}}\right)\right] \cos 4 \theta\right\} \\
F_{63}= & \frac{1}{2 G^{m} \bar{\sigma}}\left[K_{23}^{t} M_{2} \frac{b^{2}}{r^{2}} \sin 2 \theta+G_{23}^{t}\left(3 C_{2} \frac{b^{4}}{r^{4}}+2 D_{2} \frac{b^{2}}{r^{2}}\right) \sin 4 \theta\right] \\
F_{44}= & \frac{G_{12}^{f}+G^{m}}{G_{12}^{f}+G^{m}-V_{f}\left(G_{12}^{f}-G^{m}\right)}+\frac{V_{f}\left(G_{12}-G^{m}\right)}{G_{12}^{f}+G^{m}-V_{f}\left(G_{12}^{f}-G^{m}\right)}\left(\frac{b}{r}\right)^{2} \cos 2 \theta \\
F_{54}= & \frac{\left(G_{12}^{f}-G^{m}\right) V_{f}}{G_{12}^{f}+G^{m}-V_{f}\left(G_{12}^{f}-G^{m}\right)}\left(\frac{b}{r}\right)^{2} \sin 2 \theta \\
F_{26}= & \frac{G_{23}^{t}}{4 G^{m} \bar{\sigma}}\left[\left(3 C_{2} \frac{b^{4}}{r^{4}}+2 D_{2} \frac{b^{2}}{r^{2}}\right) \sin 4 \theta+2 \frac{G^{m}}{K_{23}^{m}}\left(3 B_{2} \frac{r^{2}}{b^{2}}-D_{2} \frac{b^{2}}{r^{2}}\right) \sin 2 \theta\right] \\
F_{36}= & \frac{G_{23}^{t}}{4 G^{m} \bar{\sigma}}\left[-\left(3 C_{2} \frac{b^{4}}{r^{4}}+2 D_{2} \frac{b^{2}}{r^{2}}\right) \sin 4 \theta+2 \frac{G^{m}}{K_{23}^{m}}\left(3 B_{2} \frac{r^{2}}{b^{2}}-D_{2} \frac{b^{2}}{r^{2}}\right) \sin 2 \theta\right] \\
F_{66}= & \frac{G_{23}^{t}}{2 G^{m} \bar{\sigma}}\left[-\left(2 A_{2}+6 B_{2} \frac{r^{2}}{b^{2}}\right)+\left(3 C_{2} \frac{b^{4}}{r^{4}}+2 D_{2} \frac{b^{2}}{r^{2}}\right) \cos 4 \theta\right]
\end{aligned}
$$

where $b$ is the matrix outer radius. The unknown constants, $N_{1}, M_{2}, N_{2}$, and $M_{3}$, are computed by solving Eq. (27).

$$
\left[\begin{array}{cccc}
1 & -\frac{1}{2}\left(\frac{1}{V_{f}}\right) & -1 & 0 \\
2 \frac{G_{23}^{f}}{K_{23}^{f}} & \frac{G_{23}^{f}}{G^{m}} \frac{1}{V_{f}} & -2 \frac{G_{23}^{f}}{K_{23}^{m}} & 0 \\
0 & \frac{1}{2} & 1 & -\frac{1}{2} \\
0 & -\frac{G_{23}}{G^{m}} & 2 \frac{G_{23}}{K_{23}^{m}} & 1
\end{array}\right]\left\{\begin{array}{l}
N_{1} \\
M_{2} \\
N_{2} \\
M_{3}
\end{array}\right\}=\left\{\begin{array}{c}
0 \\
0 \\
\bar{\sigma} \\
2 \frac{G_{23}}{K_{23}} \bar{\sigma}
\end{array}\right\}
$$

The remaining unknown constants, $A_{1}, B_{1}, A_{2}, B_{2}, C_{2}, D_{2}, C_{3}$, and $D_{3}$ are determined from Eq. (28).

where,

$$
[B]\{d\}=\{f\}
$$

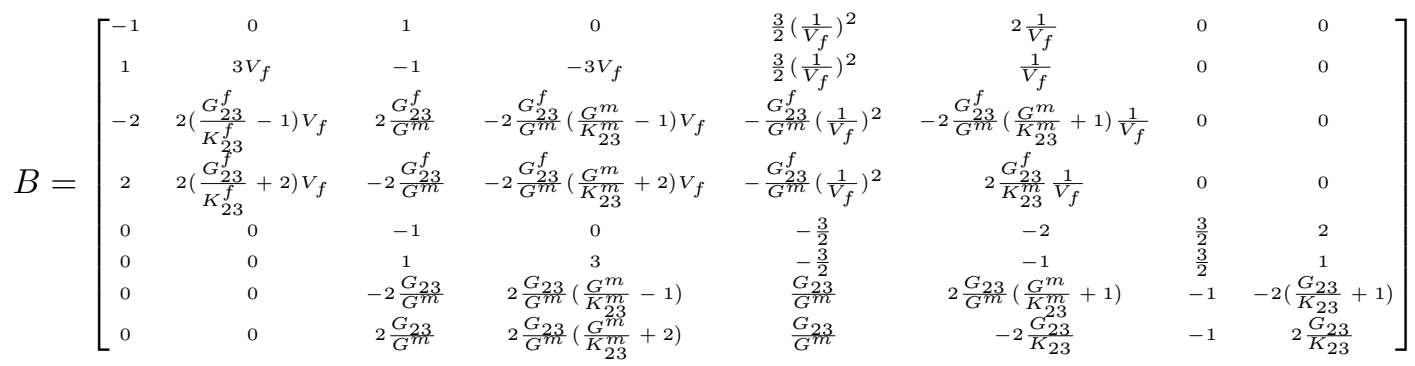

$$
\begin{aligned}
& d=\left[\begin{array}{llllllll}
A_{1} & B_{1} & A_{2} & B_{2} & C_{2} & D_{2} & C_{3} & D_{3}
\end{array}\right]^{T} \\
& f=\left[\begin{array}{llllllll}
0 & 0 & 0 & 0 & \bar{\sigma} & -\bar{\sigma} & 2 \bar{\sigma} & -2 \bar{\sigma}
\end{array}\right]^{T}
\end{aligned}
$$

